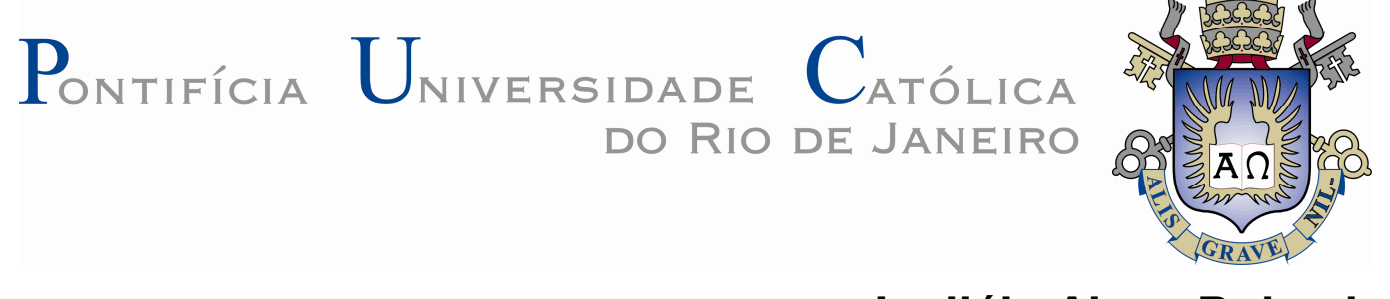

Jociléia Alves Buback

\title{
Caracterização Físico-Química-Mineralógica e Micromorfológica de um Perfil de Alteração de Rocha Alcalina do Rio de Janeiro
}

Dissertação apresentada como requisito parcial para obtenção do título de Mestre pelo Programa de PósGraduação em Engenharia Civil da PUC-Rio.

Orientador: Tácio Mauro Pereira de Campos Co-orientadores: Franklin dos Santos Antunes Claudio Palmeiro do Amaral

Rio de Janeiro, Fevereiro de 2008. 


\section{Pontifícia Universidade Catálica $_{\text {a }}$

\section{Caracterização Físico-Química-Mineralógica e Micromorfológica de um Perfil de Alteração de Rocha Alcalina do Rio de Janeiro}

Dissertação apresentada como requisito parcial para obtenção do título de Mestre pelo Programa de PósGraduação em Engenharia Civil da PUC-Rio. Aprovada pela Comissão Examinadora abaixo assinada.

Tácio Mauro Pereira de Campos

Orientador

Pontifícia Universidade Católica do Rio de Janeiro - PUC- Rio

Franklin dos Santos Antunes

Co-orientador

Pontifícia Universidade Católica do Rio de Janeiro - PUC-Rio

Claudio Palmeiro do Amaral

Pontifícia Universidade Católica do Rio de Janeiro - PUC-Rio

Co-orientador

José Tavares Araruna Júnior

Pontifícia Universidade Católica do Rio de Janeiro - PUC-Rio

Luiz Carlos Bertolino Universidade do Estado do Rio de Janeiro - UERJ

José Eugênio Leal

Coordenador Setorial do Centro Técnico Científico - PUC-Rio

Rio de Janeiro, 15 de fevereiro de 2008. 
Todos os direitos reservados. É proibida a reprodução total ou parcial do trabalho sem autorização da universidade, do autor e do orientador.

\section{Jociléia Alves Buback}

Formou-se no curso Técnico de Edificações pela Escola

Técnica Federal do Espírito Santo - ETFES em 1998. Graduou-se em Engenharia Civil na Universidade Federal do Espírito Santo - UFES em 2005.

Buback, Jociléia Alves

Caracterização

Físico-Química-Mineralógica

e Micromorfológica de um Perfil de Alteração de Rocha Alcalina do Rio de Janeiro / Jociléia Alves Buback; orientador: Tácio Mauro Pereira de Campos; co-orientadores: Franklin dos Santos Antunes, Cláudio Palmeira do Amaral. - 2008

122 f. : il. (col.) ; $30 \mathrm{~cm}$

Dissertação (Mestrado em Engenharia Civil) - Pontifícia Universidade Católica do Rio de Janeiro, Rio de Janeiro, 2008. Inclui bibliografia

1. Engenharia civil - Teses. 2. Solo residual. 3. Rocha alcalina. 4 Intemperismo. 5. Mineralogia. 6. Micromorfologia. I. Campos, Tácio Mauro Pereira de. II. Antunes, Franklin dos Santos. III. Amaral, Cláudio Palmeira. IV. Pontifícia Universidade Católica do Rio de Janeiro. Departamento de Engenharia Civil. V. Título. 
Dedico esta dissertação a meus pais, Antônio e Irene, e as minhas irmãs, Fernanda e Eliane, por acreditarem em mim 


\section{Agradecimentos}

Agradeço a minha família, por estar sempre, sempre ao meu lado. Principalmente a minha grandiosa mãe, muito obrigada mãe pelas infinitas palavras de conforto e incentivo, você "não existe", Te Amo. Ao meu pai por sempre se preocupar comigo e por ter feito de seu simples conhecimento a base e o incentivo para que eu seguisse essa profissão. As minhas irmãs pelo companheirismo constante e por sempre torcerem por mim, obrigada meninas. Sei que o Pai Celestial me ama muito, por isso colocou-me em uma família de pessoas tão especiais como vocês, que sempre me motivam e me ajudam a trilhar esse caminho.

Aos meus amigos Elvidio e Eduardo, que se empolgaram e me contagiaram, incentivando-me para que eu viesse para o Rio. Meninos, apesar de todos os previstos e imprevistos que ocorreram no decorrer desse tempo, valeu a pena. Muito obrigada por toda a força e incentivo.

A minha amiga Juliane que mesmo de longe sempre me proporcionou apoio e atenção. Jujuba, muito obrigada pela força, foi muito importante pra mim.

A minha amiga Vivian, por me ouvir sempre que precisei, pelo carinho, dedicação, prestatividade e preocupação, obrigada por tudo menina.

Agradeço aos meus amigos "cariocas", mesmo distantes jamais me esquecerei de vocês: Roberto, pelo saudoso som do violão e do $\underline{R}$ que só ele sabe falar; Guilherme, pelas infinitas ajudas nos ensaios e paciência constante, valeu por tudo Guilhermitcho; Elvidio, pela forte e constante presença nesta etapa final, muito obrigada; Viví, pela boa comida (até aprendi a gostar de torta capixaba); Hyllttonn, pelas músicas enviadas para me tranqüilizar nos momentos de sufoco e também pelas boas gargalhadas, idas a praia, a festas, obrigada garoto; Loren pela prestatividade constante; Bê, por todo auxílio nas dúvidas; Amandita pelas palavras de incentivo que me ajudaram a seguir em frente e não desanimar. Enfim, fico grata a todos por fazerem parte da minha vida nesta época do mestrado. Valeu por todos os finais de semana e madrugadas de estudo, jantares, churrascos, festas de aniversários, etc. Vou sentir muita saudade de todos vocês. 
Aos amigos do Espírito Santo em especial a Pitty, Jaque, Rosana, Beth, Amélio e Miriam. A galera da UFES, especialmente a Náthia, Valéria, Rodrigo César, Vitor Schwartz e Rodrigo Dalvi. A professora Kátia por toda colaboração e incentivo. Aos amigos do Rio, Ala Jardim Botânico, principalmente a Roberta, Joana e Mary Pessoa. A minha amiga Adriana Siqueira, muito obrigada por todo o carinho e companheirismo nessa época no Rio de Janeiro.

A empresa PCE - Projetos e Consultoria de Engenharia Ltda, em especial ao José Eduardo Moreira e a Ana Lúcia Gonçalves Maiolino.

Ao professor Tácio. Ao professor Amaral por toda a colaboração. Em especial ao professor Franklin por todo o carinho e toda disposição em ajudar, exemplo de competência e profissionalismo, jamais me esquecerei de tudo que fez por mim, muito obrigada.

Aos funcionários do DEC, Departamento de Engenharia Civil, principalmente à Rita, obrigada por toda colaboração e disponibilidade. Ao pessoal do Laboratório de Geotecnia e Meio Ambiente da PUC-Rio: "Seu José", William, Josué, Amauri (muito obrigada por toda ajuda) e a Mônica (agradeço pelo auxílio nas dúvidas).

A Dona Antônia por ter me acolhido em sua casa, a Alê que contribuiu muito para que eu permanecesse naquele local e a Amanda que chegou mais tarde, mas que influenciou significativamente.

A Empresa de Mineração de Tanguá - Emitang, especialmente ao Sr. José Maria, Guilherme, Pedro e Rafael pela constante disponibilidade.

Aos professores Ana Valéria Freire Allemão Bertolino e Luiz Carlos Bertolino, pela colaboração na análise micromorfológica. Ao Centro Brasileiro de Pesquisas Físicas, por ceder o Laboratório de Microscopia Óptica para as análises micromordológicas.

Ao Departamento de Ciência dos Materiais e Metalurgia, em especial ao Ronaldo pela realização dos ensaios de difração de raios-X e ao Mauricio e Márcia que contribuíram para a realização da Microscopia Eletrônica de 
Varredura. Ao Laboratório de Fundação de Apoio à Física e à Química da Universidade de São Carlos, principalmente ao Geraldo, responsável pela realização do ensaio de porosimetria de mercúrio. Ao Ciclo Básico, CTC, PUCRio.

Ao "Seu" Tarcisio, que confeccionou as lâminas micromorfológicas, pela simplicidade e boa vontade em sempre colaborar. Ao Professor Júlio Cezar Mendes - UFRJ pela prestatividade na realização das análises químicas. A Embrapa também pela realização das análises químicas. Ao Departamento de Recursos Minerais do Rio de Janeiro, principalmente ao Paulo (geólogo) e a Ana Paula.

Ao Geólogo Thiago Moreira Roza, fico muito grata por toda a disposição e colaboração.

A CAPES, pelo apoio financeiro.

Ao Pai Eterno, por me dar força constante em todo o mestrado. Agradeço por me conduzir até aqui, me guiando em todos os momentos e me ajudando no que parecia impossível. Muito obrigada. 


\section{Resumo}

Buback, Jociléia Alves; De Campos, Tácio Mauro Pereira; Antunes, Franklin dos Santos; Amaral, Claudio Palmeiro do. Caracterização físico-química-mineralógica e micromorfológica de um perfil de alteração de rocha alcalina do Rio de Janeiro. Rio de Janeiro, 2007. 122p. Dissertação de Mestrado - Departamento de Engenharia Civil, Pontifícia Universidade Católica do Rio de Janeiro.

Vários estudos sobre o comportamento de produtos oriundos da alteração de rochas devido à ação intempérica já foram desenvolvidos no país. Esses estudos são de grande importância para a engenharia geotécnica, principalmente em locais de clima tropical, quente e úmido, como o Brasil, já que as condições climáticas possuem uma influência significativa na formação resultante da rocha. Logo, o conhecimento detalhado da origem do solo contribui para uma melhor compreensão do seu comportamento geomecânico. Este trabalho compreende principalmente um estudo físico-químicomineralógico e micromorfológico de amostras de solo, com o propósito de analisar o comportamento das mesmas devido à ação do intemperismo. Esse material está localizado no Complexo Alcalino de Tanguá, município de Tanguá, onde as amostras foram retiradas aleatoriamente, mas com base em suas características morfológico-tátil-visuais. Ressalta-se aqui que estudos com esse enfoque desenvolvidos nesse tipo de solo e/ou rochas de origem alcalina são raramente encontrados na literatura. Portanto, a elaboração desse trabalho colabora agregando um conhecimento prévio, sobre a rocha, a materiais originários da mesma que apresentam diferentes graus de intemperização, contribuindo para uma ampliação do conhecimento geral de solos residuais como um todo. Esse estudo foi realizado dentro do contexto do projeto PRONEX-Rio, denominado "Geotecnia Aplicada à Avaliação, Prevenção e Remediação de Problemas Ambientais", em desenvolvimento junto ao Núcleo de Geotecnia Ambiental do DEC/PUC-Rio na linha de pesquisa Geotecnia Ambiental do Setor de Geotecnia do DEC/PUC-Rio.

\section{Palavras-chave}

solo residual, rocha alcalina, intemperismo, mineralogia e micromorfologia 


\section{Abstract}

Buback, Jociléia Alves; De Campos, Tácio Mauro Pereira; Antunes, Franklin dos Santos; Amaral, Claudio Palmeiro do. Residual soil alkaline origin characterization at the Tanguá city, Rio de Janeiro. Rio de Janeiro, 2007. 122p. MSc. Dissertation - Department of Civil Engineering, Pontifícia Universidade Católica do Rio de Janeiro.

The behavior of rock decomposition products has been studied by many authors throughout the country. These works have great importance for the geotechnical engineering, mainly in tropical regions, with hot and rainy climates, like it is found in Brazil, since atmospheric conditions have a great influence in the soil formation originated from the mother rock. Therefore the detailed knowledge of the soil origin provides a better understanding of its geomechanical behavior. This work deals with a physical-chemicalmineralogical and micromorphological study of arbitrary soil points on the Tanguá alkaline complex, at the Tanguá Municipality (Rio de Janeiro State, Brazil). The main subject of the present work is to analyze effects of weathering on the physical-chemical-mineralogical and structural characteristics of the residual soil derived from the alkaline rock found in Tanguá, as well as on some simple hydro-mechanical characteristics of the material. It's important to note here that works on this type of rock and/or soil are rarely found in the literature. Thus, this work contributes towards a better understanding on the behaviour of residual soils as a whole.This study has been done within the context of the PRONEX-Rio project named "Geotechnics Applied to the Evaluation, Prevention and Remediation of Environmental Problems", under development within the Environmental Geotechnics Group of DEC/PUC-Rio.

\section{Palavras-chave}

Residual soil, alkaline rock, weathering, mineralogy and micromorphology 


\section{Sumário}

1 Introdução 22

2 Intemperismo e Rocha Alcalina 24

3 Descrição da Área de Estudo e Amostragem 28

3.1. Meio físico 28

3.1.1. Localização 28

3.1.2. Vegetação e condições climáticas do local 30

3.1.3. Geologia e geomorfologia 31

3.2. Amostragem 33

3.2.1. Coleta de amostras 33

3.2.2. Características morfológicas do solo 37

4 Ensaios de Laboratório $\quad 40$

4.1. Caracterização física 41

4.1.1. Análise granulométrica 42

4.1.2. Limites de Atterberg 42

4.1.3. Massa específica dos grãos 43

4.2. Porosimetria de mercúrio 43

4.3. Caracterização química 46

4.3.1. Análise química total 46

4.3.2. Análise química parcial $\quad 46$

4.3.3. $\mathrm{pH}$, matéria orgânica e condutividade elétrica 47

4.4. Caracterização mineralógica 48

4.4.1. Observação em lupa binocular 48

4.4.2. Difração de raios- $X \quad 49$

4.4.3. MEV - Microscópio eletrônico de varredura 51

4.4.4. Micromorfologia dos solos 52

4.5. Ensaio de curva característica de sucção 53

4.6. Ensaio de tração - Método Brasileiro 55

4.7. Ensaio de desagregabilidade $\quad 57$

5 Apresentação e Discussão dos Resultados 58 
5.1. Caracterização física 58

5.1.1. Análise granulométrica 58

5.2. Porosimetria de mercúrio $\quad 64$

5.3. Caracterização química $\quad 67$

5.3.1. Análise química total 67

5.3.2. Análise química parcial 69

5.3.3. Matéria orgânica, $\mathrm{pH}$ e condutividade elétrica 71

5.4. Caracterização mineralógica 74

5.4.1. Observação em lupa binocular $\quad 74$

5.4.2. Difração de raios-X 76

5.4.3. MEV - Microscópio eletrônico de varredura 80

5.4.4. Micromorfologia 84

5.4.5. Curva característica de sucção 92

5.4.6. Compressão diametral 101

$\begin{array}{ll}\text { 5.4.7. Desagregabilidade } & 106\end{array}$

6 Conclusões e Sugestões para Trabalhos Futuros 112

6.1. Conclusões 112

6.2. Sugestões para trabalhos futuros $\quad 114$

$\begin{array}{ll}\text { Referências Bibliográficas } & 116\end{array}$

ANEXO I Mapa Geológico da Área de Estudo 124 


\section{Lista de Figuras}

Figura 3-1- Localização - BR 101. (Fonte: www.tangua.rj.gov.br).

Figura 3-2 - Localização dos pontos de coleta das amostras 01 e 02, próximo ao shaft 01 (desativado) da empresa de mineração de Tanguá. (Fonte: Google Earth).

Figura 3-3 - Localização dos pontos de coleta das amostras 03, 04, 05 e 06, próximo ao shaft 02 (em atividade) da empresa de mineração de Tanguá. (Fonte: Google Earth).

Figura 3-4 - Estação base do GPS, shaft 01.

Figura 3-5 - GPS no local de coleta da amostra 03.

Figura 3-6 - Mapa geológico regional (Becker et al., 1997). 32

Figura 3-7 - Local de retirada da amostra 02.

Figura 3-8 - Local de retirada da amostra $03 . \quad 35$

Figura 3-9 - Local de retirada da amostra 04.

Figura 3-10 - Preparação dos blocos em campo, amostra 02.

Figura 3-11 - Preparação dos blocos em campo, amostra 02.

Figura 3-12 - Afloramento de rocha alcalina. 37

Figura 3-13 - Detalhe de um lajão do afloramento de rocha alcalina. 37

Figura 3-14 - Amostra 02 evidenciando a presença de veios. 38

Figura 3-15 - Amostra 03 indicando as características reliquiares da rocha mãe.

Figura 3-16 - Amostra 04 evidenciando características reliquiares da rocha mãe.

Figura 3-17 - Concreções brancas - presença de feldspato alterado (caulinita).39 Figura 4-1 - Micromeritics Pore Sizer 9320 - Laboratório de Fundação de Apoio à Física e à Química da Universidade de São Carlos. 45 Figura 4-2 - Difratômetro de raios-X.

Figura 4-3 - Microscópio Eletrônico de Varredura. 52

Figura 5-1 - Curvas granulométricas com defloculante (Hexametafosfato de sódio). $\quad 59$

Figura 5-2 - Curvas granulométricas sem defloculante (Água destilada). $\quad 59$

Figura 5-3 - Fração fina das amostras de solo. $\quad 60$

Figura 5-4 - Atividade das três amostras de solo. $\quad 61$

Figura 5-5 - Índice de vazios e porosidade de cada amostra de solo. 63 
Figura 5-6 - Peso específico natural e peso especifico aparente seco de cada amostra de solo. 63

Figura 5-7 - Grau de saturação de cada amostra de solo. 64

Figura 5-8 - Curvas obtidas pelo ensaio de porosimetria de mercúrio. $\quad 65$

Figura 5-9 - Curvas obtidas através do ensaio de porosimetria de mercúrio classificação por Brewer (1976). $\quad 66$

Figura 5-10 - Variação de Ki e Kr. 70

Figura 5-11 - Variação do teor de matéria orgânica. 72

Figura 5-12 - Variação de pH. 73

Figura 5-13 - Amostra 02 - Pedregulho e areias grossa, média e fina. $\quad 74$

Figura 5-14 - Amostra 03 - Pedregulho e areias grossa, média e fina. $\quad 75$

Figura 5-15 - Amostra 04 - Pedregulho e areias grossa, média e fina. $\quad 75$

Figura 5-16 - Difratograma da amostra 02 (método do pó) - areia fina, silte e argila, sem tratamento. Ensaio realizado no Difratômetro de marca Siemens, Modelo D-5000. 76

Figura 5-17 - Difratograma da amostra 02 - fração argila, apresentada na forma natural, aquecida e glicolada. Ensaio realizado no Difratômetro de marca Siemens, Modelo D-5000. I - ilita; C - Caulinita; Fk - Feldspato potássico; Fd - Feldspatóide.

77

Figura 5-18 - Difratograma da amostra 03 (método do pó) - areia fina, silte e argila, sem tratamento. Ensaio realizado no Difratômetro de marca Siemens, Modelo D-5000.

77

Figura 5-19 - Difratograma da amostra 03 fração argila. Apresentada na forma natural, aquecida e glicolada. Ensaio realizado no Difratômetro de marca Siemens, Modelo D-5000. Cl - Clorita; I - llita; C - Caulinita; Fd Feldspatóide.

Figura 5-20 - Difratograma da amostra 04 (método do pó) - areia fina, silte e argila, sem tratamento. Ensaio realizado no Difratômetro de marca Siemens, Modelo D-5000 C - Caulinita; Fk - Feldspato potássico.

78

Figura 5-21 - Difratograma da amostra 04 - fração argila. Apresentada na forma natural, aquecida e glicolada. Ensaio realizado no Difratômetro de marca Siemens, Modelo D-5000. I - ilita; C - Caulinita; Fk - Feldspato potássico.

Figura 5-22 - Imagem da amostra 02 e EDS dos pontos analisados. 79

Figura 5-23 - Imagem da amostra 03 e EDS dos pontos analisados. 81

Figura 5-24 - Imagem da amostra 04 e EDS dos pontos analisados. 82 83 
Figura 5-25 - Fotomicrografia da amostra 02 - Grãos parcialmente preservados.

Aumento de 5 vezes. Nicóis cruzados. Fp - Feldspato.

Figura 5-26 - Fotomicrografia da amostra 02 - Impregnação de hidróxido de ferro. Aumento de 5 vezes. Luz plana. Fe - Hidróxido de Ferro.

85

Figura 5-27 - Fotomicrografia da amostra 02 - Grão de feldspatóide parcialmente alterado. Aumento de 5 vezes. Nicóis cruzados. Fd - Feldspatóide.

86

Figura 5-28 - Fotomicrografia da amostra 02 - Grão caulinitizado. Aumento de 5 vezes. Nicóis cruzados. Fp - Feldspato.

Figura 5-29 - Fotomicrografia da amostra 03 - Plasma com hidróxido de ferro e alta quantidade de poros. Aumento de 5 vezes. Nicóis cruzados. Fe Hidróxido de ferro.

Figura 5-30 - Fotomicrografia da amostra 03 - Grão de pirita alterado. Aumento de 10 vezes. Luz plana. Pi - Pirita.

Figura 5-31 - Fotomicrografia da amostra 03 - Feldspatóides alterados. Aumento de 5 vezes. Nicóis cruzados. Fd - Feldspatóide.

Figura 5-32 - Fotomicrografia da amostra 04 - Microporos presentes no plasma. Aumento de 10 vezes. Nicóis cruzados.

Figura 5-33 - Fotomicrografia da amostra 04 - Mineral secundário, possivelmente ilita. Aumento de 10 vezes. Nicóis cruzados. I - llita. 90

Figura 5-34 - Fotomicrografia da amostra 04 - Presença de minerais opacos. Aumento de 10 vezes. Luz plana.

Figura 5-35 - Fotomicrografia da amostra 04 - Mica parcialmente alterada. Aumento de 10 vezes. Nicóis cruzados. Mi - Mica.

Figura 5-36 - Amostra 02 - Curva característica de sucção em função da umidade volumétrica.

Figura 5-37 - Amostra 03 - Curva característica de sucção em função da umidade volumétrica.

Figura 5-38 - Amostra 04 - Curva característica de sucção em função da umidade volumétrica.

Figura 5-39 - Amostra 02 - Comparação entre a curva característica de sucção e a curva característica obtida pelo ensaio de porosimetria de mercúrio em função da umidade volumétrica.

Figura 5-40 - Amostra 03 - Comparação entre a curva característica de sucção e a curva característica obtida pelo ensaio de porosimetria de mercúrio em função da umidade volumétrica. 
Figura 5-41 - Amostra 04 - Comparação entre a curva característica de sucção e a curva característica obtida pelo ensaio de porosimetria de mercúrio em função da umidade volumétrica.

Figura 5-42 - Amostra 02 - Curva característica de sucção em função do grau de saturação.

Figura 5-43 - Amostra 03 - Curva característica de sucção em função do grau de saturação.

Figura 5-44 - Amostra 04 - Curva característica de sucção em função do grau de saturação.

Figura 5-45 - Amostra 02 - Curva característica de sucção em função da umidade gravimétrica. 100

Figura 5-46 - Amostra 03 - Curva característica de sucção em função da umidade gravimétrica. 100

Figura 5-47 - Amostra 04 - Curva característica de sucção em função da umidade gravimétrica. 101

Figura 5-48 - Ensaio de compressão diametral em solo com menor teor de umidade. Amostra $02 . \quad 102$

Figura 5-49 - Ensaio de compressão diametral em solo com maior teor de umidade. Amostra $03 . \quad 102$

Figura 5-50 - Início do ensaio. Amostra 02.

Figura 5-51 - Início da formação da trinca de tração. Amostra 02.

Figura 5-52 - Aumento da formação da trinca com o avanço das deformações. Amostra 02.

Figura 5-53 - Ruptura total da amostra de solo. Amostra 02.

Figura 5-54 - Início da formação da trinca. Amostra 04.

Figura 5-55 - Abertura da trinca com a aplicação da força. Amostra 04.

Figura 5-56 - Maior abertura da trinca com o avanço da deformação. Amostra $04 . \quad 104$

Figura 5-57 - Ruptura parcial do corpo de prova - apresentação da heterogeneidade. Amostra $04 . \quad 104$

Figura 5-58 - Amostra 02 - Relação da resistência à tração com o teor de umidade gravimétrica. 105

Figura 5-59 - Amostra 03 - Relação da resistência à tração com o teor de umidade gravimétrica. 105

Figura 5-60 - Amostra 04 - Relação da resistência à tração com o teor de umidade gravimétrica. 106

Figura 5-61 - Preparação das amostras para a realização do ensaio. 107 
Figura 5-62 - Amostras no início do ensaio de desagregabilidade por imersão progressiva - água na altura da base dos corpos de prova.

Figura 5-63 - Amostras no ensaio de imersão progressiva - água a 1/3 da altura dos corpos de prova.

Figura 5-64 - Amostras no ensaio de imersão progressiva - água a 2/3 da altura dos corpos de prova.

108

Figura 5-65 - Amostras no ensaio de imersão progressiva - água a 3/3 da altura dos corpos de prova, ou seja, imersão total da amostra, após 24 horas. 108

Figura 5-66 - Amostras no ensaio de imersão total - imediatamente após a inundação.

109

Figura 5-67 - Amostras no ensaio de imersão total - 15 minutos após a inundação.

109

Figura 5-68 - Amostras no ensaio de imersão total - 30 minutos após a inundação.

110

Figura 5-69 - Amostras no ensaio de imersão total - 1 hora após a inundação.

Figura 5-70 - Amostras no ensaio de imersão total - 24 horas após a inundação. 


\section{Lista de Tabelas}

Tabela 3-1 - Coordenadas dos locais onde foram coletadas as amostras.........30

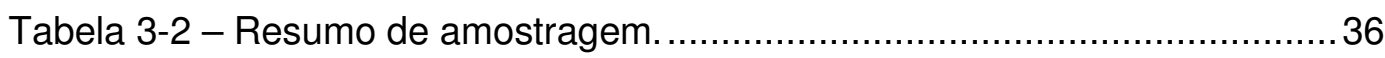

Tabela 5-1 - Resultados dos ensaios de caracterização com defloculante (Hexametafosfato de sódio). 61

Tabela 5-2 - Resultados dos ensaios de caracterização sem defloculante (Água

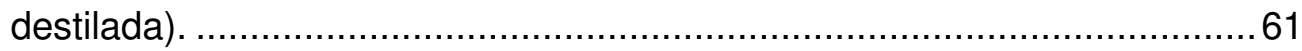

Tabela 5-3 - Índices físicos obtidos por correlação.......................................... 62

Tabela 5-4 - Densidade relativa dos grãos de alguns minerais (adaptado de

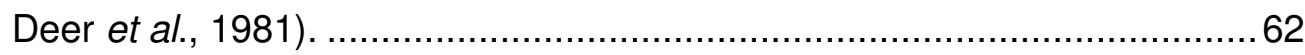

Tabela 5-5 - Porosidade obtida pelo ensaio de porosimetria de mercúrio. ........66 67

Tabela 5-6 - Concentração de índices químicos. ............................................68

Tabela 5-7 - Análise química parcial - ataque sulfúrico. ................................69

Tabela 5-8 - Análise química parcial - complexo sortivo................................69

Tabela 5-9 - pH, matéria orgânica e condutividade elétrica............................. 71

Tabela 5-10 - Minerais identificados na difração de raios-X............................79

Tabela 5-11 - Freqüência - porcentagem da área da lâmina...........................91

Tabela 5-12 - Valores de entrada de ar e umidade residual das três amostras de

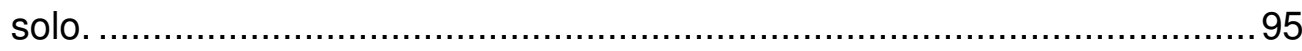




\section{Lista de Abreviaturas}

ABNT = Associação Brasileira de Normas Técnicas

$\mathrm{C} . \mathrm{E}=$ Condutividade elétrica

CNPS $=$ Centro Nacional de Pesquisa de Solos

CPS = Contagem por segundo

CTC = Capacidade de troca catiônica

DCMM = Departamento de Ciência dos Materiais e Metalurgia

$\mathrm{DEC}=$ Departamento de Engenharia Civil

$E D S=$ Analisador de energia dispersiva

EMBRAPA $=$ Empresa Brasileira de Pesquisas Agrárias

$M E V$ = Microscópio eletrônico de varredura

P.F. = Índice de perda ao fogo 


\section{Lista de Símbolos}

$\mathrm{Al}=$ alumínio

$\mathrm{Al}^{+3}=$ cátion de Alumínio

$\mathrm{Ba}=$ bário

$\mathrm{Ca}=$ cálcio

$\mathrm{Ca}^{+2}=$ cátion de cálcio

$\mathrm{Cr}=$ cromo

$\mathrm{cm}=$ centímetro

$\mathrm{e}=$ índice de vazios

$\mathrm{g}=$ aceleração da gravidade

$\mathrm{G}_{\mathrm{s}}=$ densidade relativa dos grãos

$\mathrm{H}^{+}=$cátion de hidrogênio

$\mathrm{Hg}=$ mercúrio

la = índice de atividade de Skempton

IP = índice de Plasticidade

$\mathrm{K}=$ potássio

$\mathrm{K}^{+}=$cátion de potássio

$\mathrm{kg}=$ quilograma

$\mathrm{kPa}=$ quilopascal

$\mathrm{L}=$ litro

$\mathrm{LL}=$ limite de liquidez

$\log =$ logaritmo

$\mathrm{LP}=$ limite de plasticidade;

$\mathrm{M}=$ metro

meq $=$ miliequivalentes

$\mathrm{Mg}=$ magnésio

$\mathrm{Mg}^{+2}=$ cátion de magnésio

$\mathrm{Mn}=$ manganês

$\mathrm{ml}=$ mililitro

$\mathrm{mm}=$ milímetro

$\mathrm{n}=$ porosidade

$\mathrm{Na}=$ sódio

$\mathrm{Nb}=$ nióbio 
$\mathrm{P}=$ fósforo

$\mathrm{pH}=$ potencial de hidrogenização

$\mathrm{Rb}=$ Rubídio

$\mathrm{S}=$ grau de saturação

$\mathrm{S}=$ enxofre

$\mathrm{s}=$ segundo

$\mathrm{Si}=$ silício

$\mathrm{Sr}=$ estrôncio

$\mathrm{T}=$ capacidade de troca catiônica

$\mathrm{w}_{\text {nat }}=$ umidade natural

$\mathrm{Y}=$ ítrio

$\mathrm{Zr}=$ zircônio

\# = diâmetro da abertura da malha da peneira

$\%=$ porcentagem

$\stackrel{0}{=}$ graus

$\gamma=$ peso específico

$\gamma_{d}=$ peso específico seco

$\gamma_{n}=$ peso específico natural

$\gamma_{w}=$ peso específico da água

$\theta=$ teor de umidade volumétrico

$\rho_{\mathrm{s}}=$ massa específica dos grãos de solo

$\rho_{\mathrm{w}}=$ densidade da água

$\Psi=$ sucção 
"Um homem demonstra ter verdadeira inteligência quando toma um assunto que é misterioso e grandioso por si mesmo e o desvenda e simplifica, de modo que até uma criança consiga compreendê-lo" 